\title{
Numerical Simulation on Reinforced Concrete Beam with Different Cover Size under Two Point Bending Load
}

\author{
R Padma Rani ${ }^{1}$ | R Harshani ${ }^{2}$ \\ ${ }^{1}$ Department of Civil Engineering, Sri Bharathi Engineering College for Women, Kaikkurichi. \\ ${ }^{2}$ Department of Civil Engineering, Ramco Insititute of Technology, Rajapalyam.
}

To Cite this Article

R Padma Rani \& R Harshani. Numerical Simulation on Reinforced Concrete Beam with Different Cover Size under Two Point Bending Load. International Journal for Modern Trends in Science and Technology 7, 39-43 (2021).

Article Info

Received on 15-April-2021, Revised on 27-April-2021, Accepted on 01-May-2021, Published on 05-May-2021.

\section{ABSTRACT}

Structural analysis is used to assess the behavior of engineering structures under the application of loads. Usually, structural analysis methods include analytical,experimental and numerical methods is used in thisproject, however, only Analytical method is used and the values are taken from literature reference, to get familiar with Finite Element Analysis (FEA) using ANSYS, this is done to acquire practical knowledge about of the effect of the cover. The aim is to identify different failure modes under a range of loading conditions by changing the cover size to get the data of various parameters such as deflection, stress etc. Study of cover helps to observe the stability, reliability and the overall strength of the structural beam. This project attempts made to study the effect of cover on the behavior of reinforced concrete beam. Forthis analytical study, the Reinforced concrete beam specimen of 2000x100x200mm was considered.ANSYS software is a suite of engineering simulation software, based on finite element method, which can solve problems ranging from linear analysis to nonlinear analysis. The Doubly reinforced beams weremodeled by using geometry. In this model,various covers are provided. The beam specimensused in this study were tested under two-point static loading condition until failure of the specimen. From theobtained resultconcluded that the total deformation and directional deformation values are low in $25 \mathrm{~mm}$ cover compared to other cases but the equivalent stress value is low in $35 \mathrm{~mm}$ cover size compared to $25 \mathrm{~mm}$ cover size.

KEYWORDS: Finite Element Analysis, ANSYS, Concrete Block, Reinforced Concrete Beam

\section{INTRODUCTION}

Concrete is one of the important construction materials in the world. Reinforced concrete beam has specific concrete block sizes. By changing the dimension of the concrete block, their properties like strength, stress, deformation, etc vary.For this study, optimum block size has been taken the effect of cover depth on the behavior of RC beams was studied using ANSYS Workbench®. The results obtained from finite element models are in good agreement with the test data. Cover protect against corrosion and weathering effect. Finding the effect of cover depth on behavior of RC beam requires maintaining long lasting life of the reinforced concrete beam. Cover in the reinforcement bars corrode due to bad weathering effect. A cover block is usually a space that is used to lift the rebar in the surface so that the concrete may flow below the reinforcement. While doing 
RCC work, it is necessary to infix the steel in the concrete (also known as cover) so that the steel bar doesn't corrode and also provides fire resistance to the steel. If the concrete block is not provided in the structure it will corrode the steel and will result in early failure of the structure. Thus, using concrete cover blocks improves the life of the structure significantly. Concrete cover blocks are frequently used in the construction of hotels, homes, bridges and other structures or projects requiring long lasting life and durability. Concrete and steel bond perfect. Hence it no cracks. The compressive strength is also not less than the environment concrete. These lowis water absorption and it also sustains extreme heat. There is no occur during curing and ensures proper concrete cover block. It also fixes to the reinforcement

\section{STRUCTURE OF PAPER}

The paper is organized as follows: In Section 1 , the introduction of the paper is provided along with the structure, important terms, objectives and overall description. In Section 2 we discuss materials and methods used for simulation. In Section 3 we have the information about finite element simulation. Section 4 shares information about the modeling of the reinforced concrete beam using ANSYS and their simulation. Section 5 tells us about the results and discussion. Section 6 tells us about the future scope and concludes the paper with references.

\section{OBJECTIVES}

The aim is to identify different failure modes under a range of loading conditions, by changing the cover size to get the data of various parameters such as deflection, stress etc. Study of cover helps to observe the stability, reliability and the overall strength of the structural beam. It also helps to maintain the bond strength throughout the concrete.

\section{Materials ANd Methods}

The doubly reinforced beam specimen sizes were of $100 \mathrm{~mm}$ width and $200 \mathrm{~mm}$ depth in cross section. Doubly reinforced beam wasof $2000 \mathrm{~mm}$ in length and it was simply supported over an effective span of $1900 \mathrm{~mm}$. The clear cover of the beam was $25 \mathrm{~mm}$. The test specimen was mounted on to a loading frame of $1000 \mathrm{kN}$ capacity. The load was applied on two points of $633 \mathrm{~mm}$ away from center of the beam towards the support. It was decided to take the section of M30 grade concrete Fe 415 HYSD bar. While calculation, the beam size was chosen, then by drawing its cross section it was understood that with different cover size the property through different cross section of same dimension but different cover size at top and bottom ( $25 \mathrm{~mm}$ size remains same along longitude) can be found out. For example: $15 \mathrm{~mm}$ cover at vertical position and $25 \mathrm{~mm}$ remains in horizontal position. The standard cover size was fixed as $25 \mathrm{~mm}$. The remaining are changed at top and bottom with prior to respective size next two sizes in ascending and descending order chosen for the test. Calculating using basic subtraction and addition cover varied in modeling the beam.

Table 1. Material Properties of a Beam

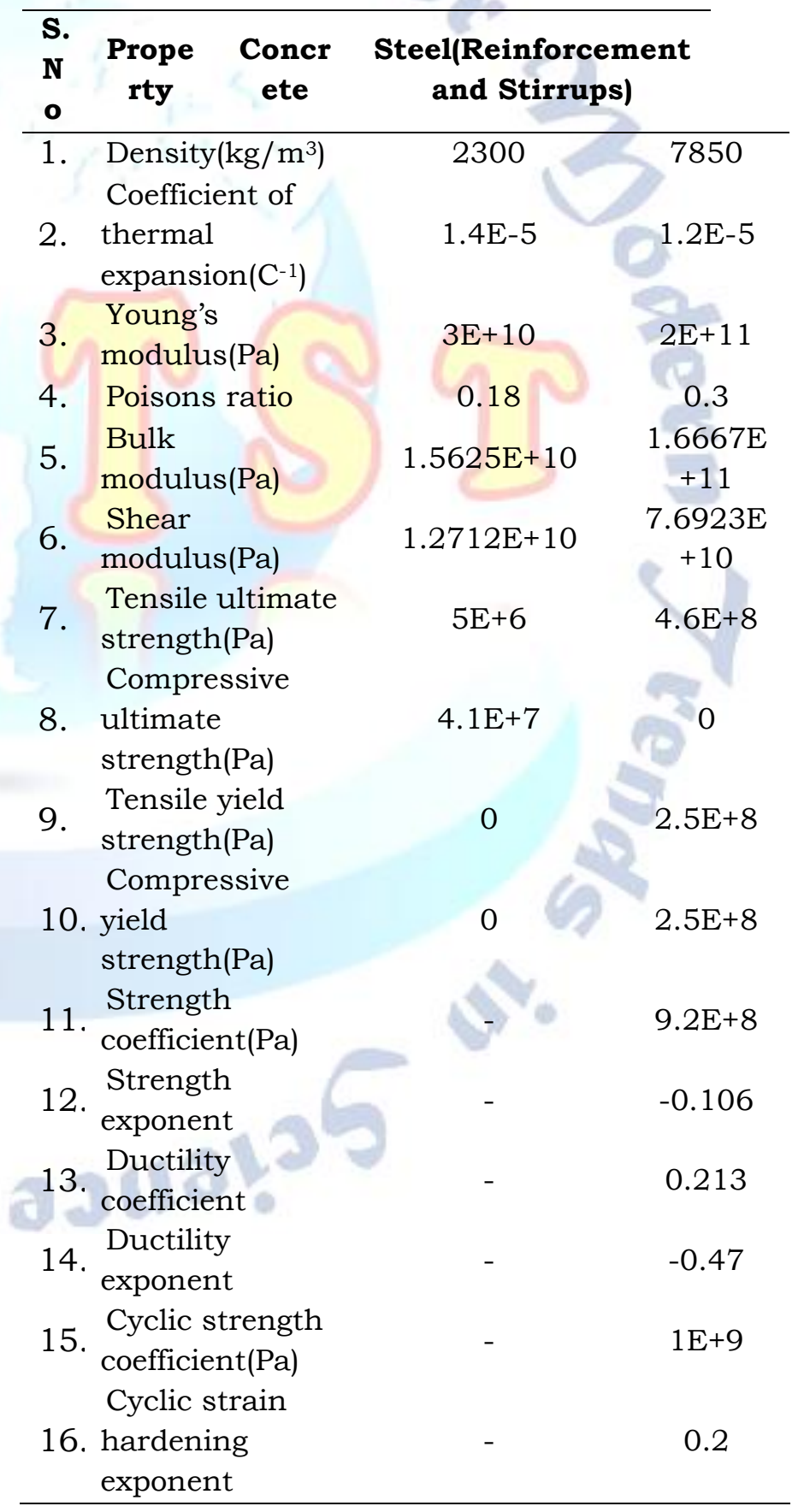




\section{FINITE ELEMENT SIMULATION}

The specimen is of $2000 \mathrm{~mm}$ length and $100 \mathrm{~mm}$ breadth, $200 \mathrm{~mm}$ thick.ANSYS preprocessing consists of geometry and modeling the object. The composite materials are analyzed by explicit conditions in ANSYS Workbench ${ }^{\circledR}$. The ANSYS explicit dynamics were used to analyses the physical properties of short-duration events for models that undergo transient dynamic forces. In this model meshing have Mesh size- $0.5 \mathrm{~mm}$, Number of nodes-93639, Number of elements-68449.

Table 2.Dimension of the section

\begin{tabular}{|l|c|}
\hline Type of beam & $\begin{array}{c}\text { Doubly Reinforced } \\
\text { Beam }\end{array}$ \\
\hline $\begin{array}{l}\text { Length of the } \\
\text { beam }\end{array}$ & $2000 \mathrm{~mm}$ \\
\hline $\begin{array}{l}\text { Width of the } \\
\text { beam }\end{array}$ & $100 \mathrm{~mm}$ \\
\hline $\begin{array}{l}\text { Depth of the } \\
\text { beam }\end{array}$ & $200 \mathrm{~mm}$ \\
\hline $\begin{array}{l}\text { Main Steel } \\
\text { bars }\end{array}$ & $\begin{array}{c}\text { Top steel }-2 \mathrm{nos} \# 10 \\
\mathrm{~mm}, \text { bottom steel - } \\
2 \mathrm{nos} \# 12 \mathrm{~mm}\end{array}$ \\
\hline Stirrups & $8 \mathrm{~mm}$ \\
& $\begin{array}{r}\text { diameter@ } 125 \mathrm{~mm} \mathrm{c} / \mathrm{c} \\
\text { spacing }\end{array}$ \\
\hline Clear cover & $\begin{array}{c}15 \mathrm{~mm}, 20 \mathrm{~mm}, 25 \mathrm{~mm} \\
\text {,30mm,35mm }\end{array}$ \\
\hline Section type & Under reinforced \\
\hline $\begin{array}{l}\text { Support } \\
\text { conditions }\end{array}$ & $\begin{array}{r}\text { Simply supported } \\
\text { beam }\end{array}$ \\
\hline
\end{tabular}

\section{MODELLING OF REINFORCED CONCRETE BEAM}

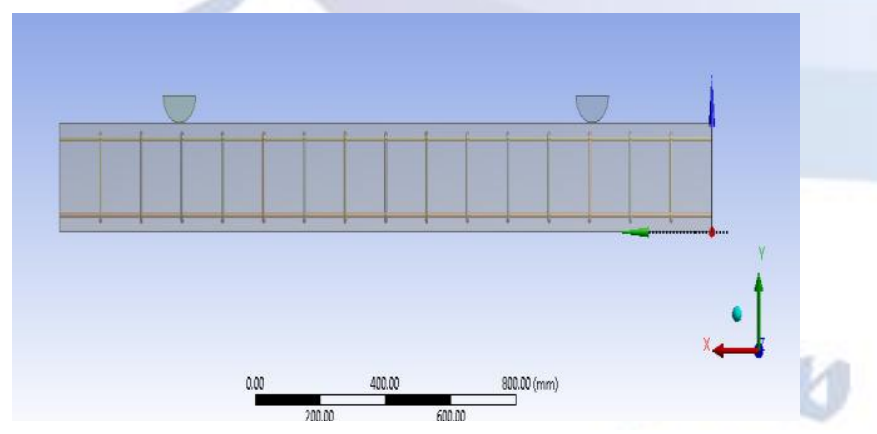

Fig. 1 Geometrical construction of Reinforced beam

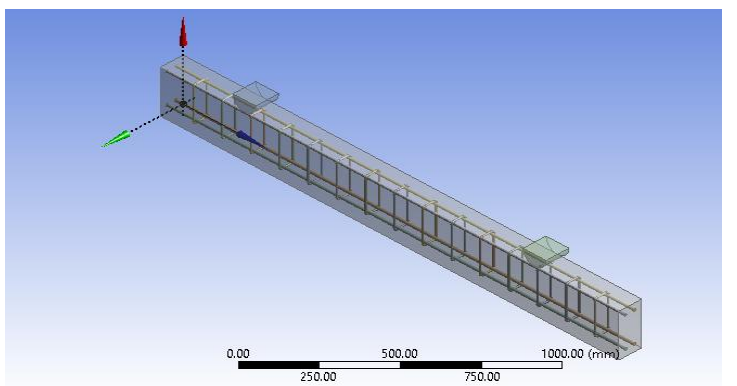

Fig. 2 Longitudinal view of specimen for $25 \mathrm{~mm}$

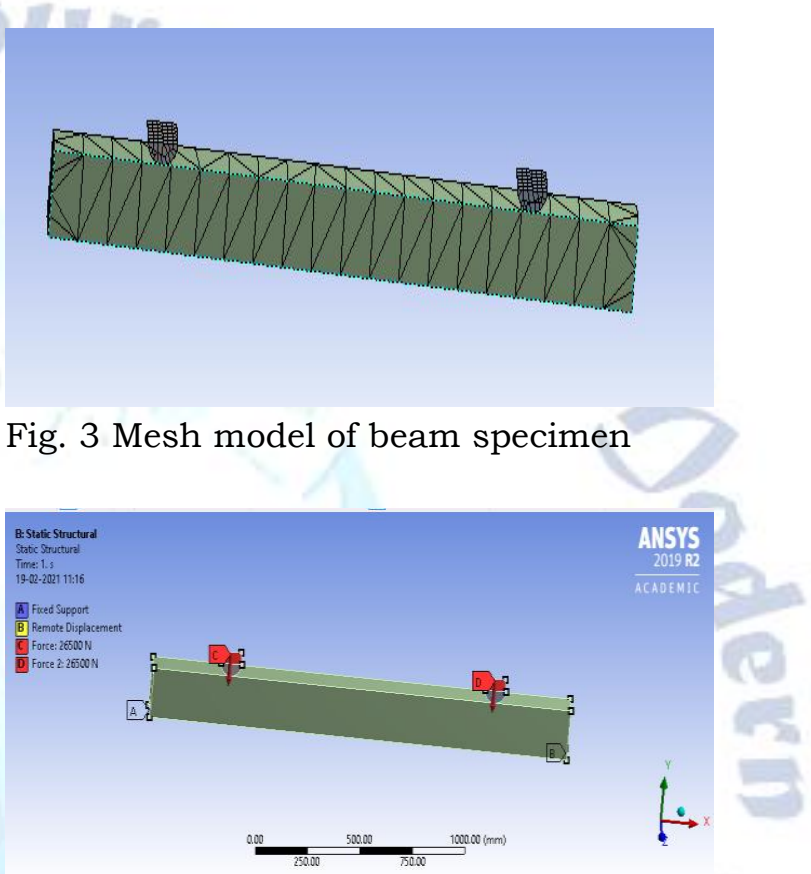

Fig. 4 Boundary conditions

\section{RESULTS AND DISCUSSION}

The problem was solved using ANSYS. It gave displacements and stress as output. The test properties ofthe steel like first crack, breaking load and deformation are taken from the journal [1],

- The total deformation adds the information about deformation length a material experiences upon the given breaking load.

- Equivalent stress is used when there is a multiracial stress state with multiple stress components acting at the same time in the structure.

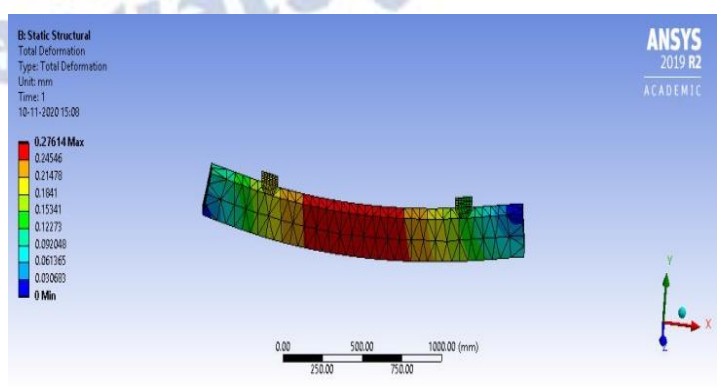

Fig. 5 Total deformation of $15 \mathrm{~mm}$ cover. 


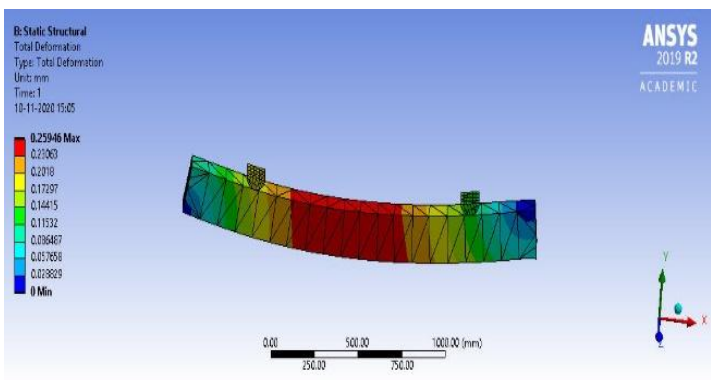

Fig. 6 Total deformation of $20 \mathrm{~mm}$ cover.

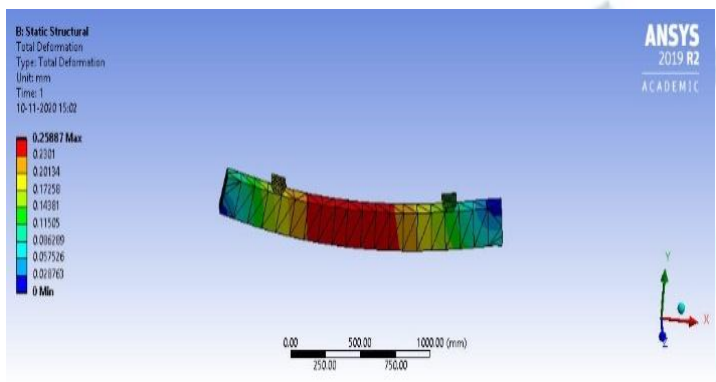

Fig. 7 Total deformation of $25 \mathrm{~mm}$ cover.

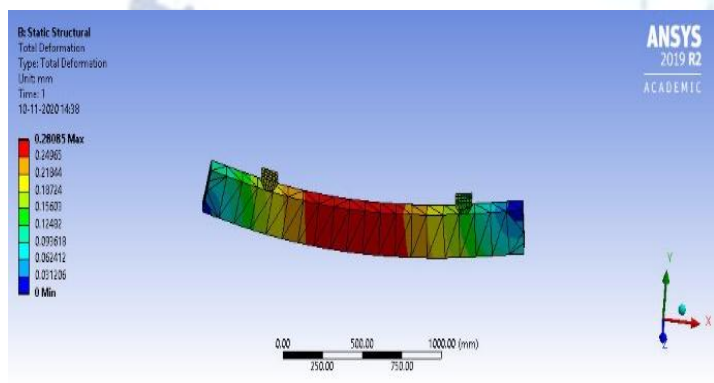

Fig. 8 Total deformation of $30 \mathrm{~mm}$ cover.

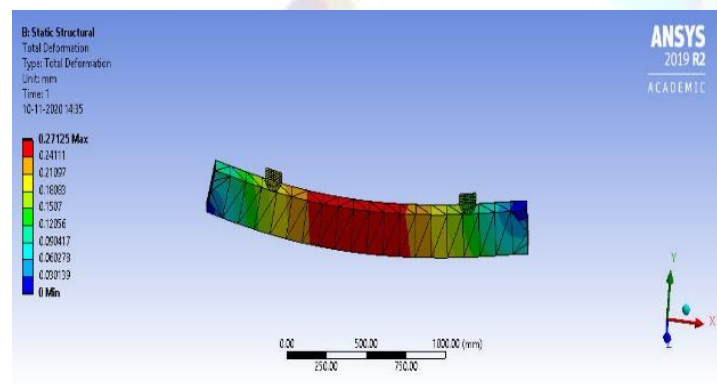

Fig. 9 Total deformation of $35 \mathrm{~mm}$ cover.

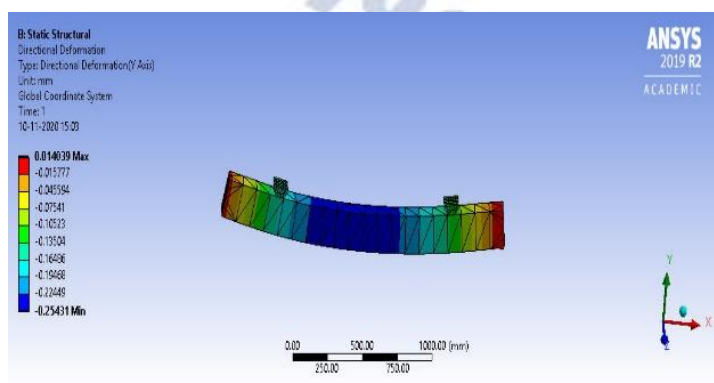

Fig. 10 Directional deformation of $25 \mathrm{~mm}$ cover.

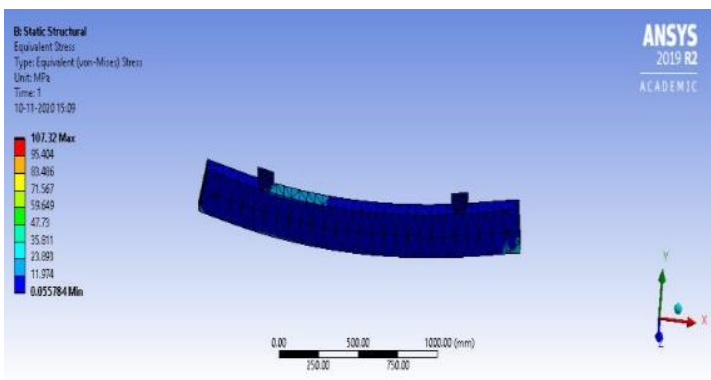

Fig. 11 Stress plot of $15 \mathrm{~mm}$ cover.

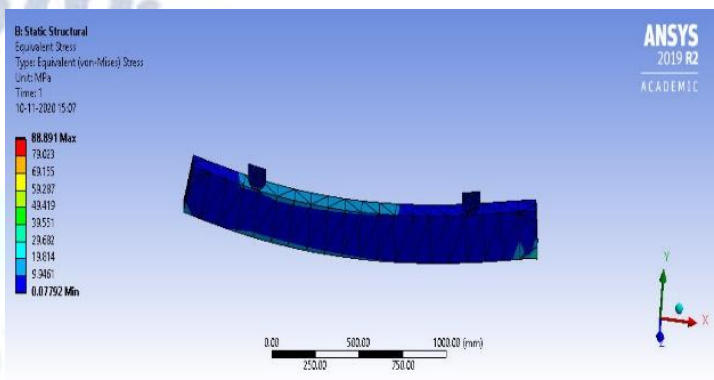

Fig. 12 Stress plot of $20 \mathrm{~mm}$ cover.

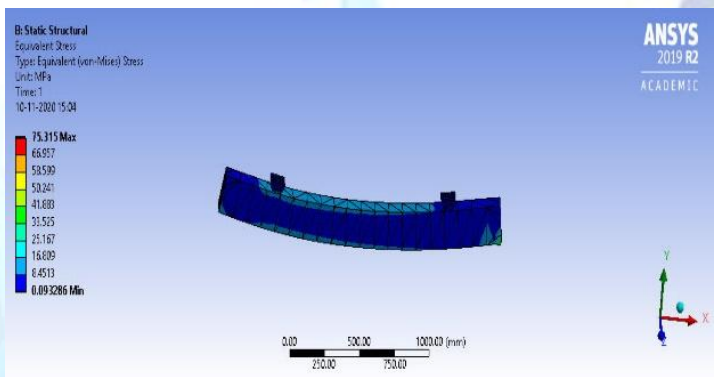

Fig. 13 Stress plot of $25 \mathrm{~mm}$ cover.

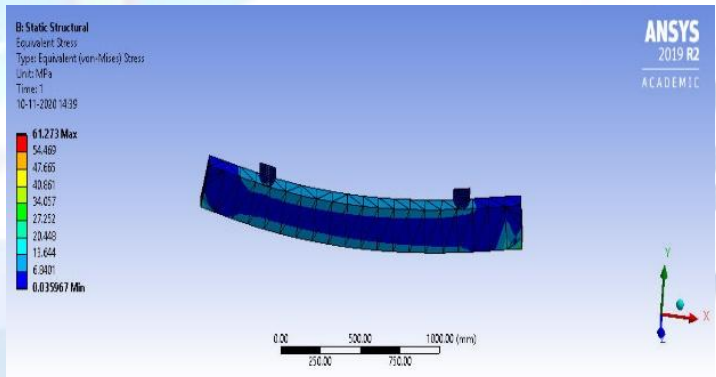

Fig. 14 Stress plot of $30 \mathrm{~mm}$ cover.

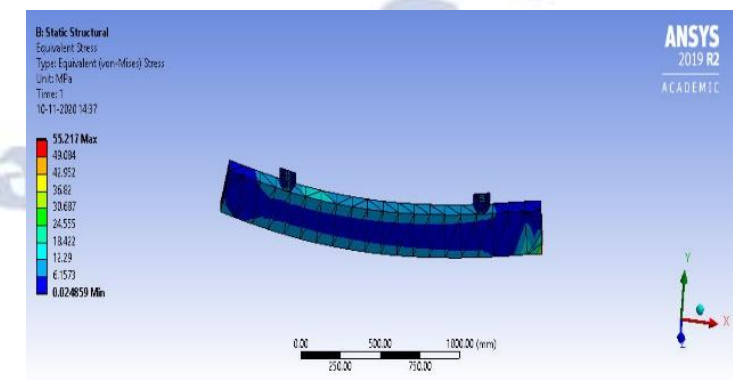

Fig. 15 Stress plot of $35 \mathrm{~mm}$ cover.

Table 3 Simulation results with different cover size 


\begin{tabular}{cccc}
\hline $\begin{array}{c}\text { Cover } \\
\text { Size } \\
\text { (mm) }\end{array}$ & $\begin{array}{c}\text { Total } \\
\text { Deformation } \\
\text { ( } \mathbf{~ m m )}\end{array}$ & $\begin{array}{c}\text { Directional } \\
\text { Deformation } \\
\text { (mm) }\end{array}$ & $\begin{array}{c}\text { Equivalent } \\
\text { Stress } \\
\text { (N/mm } \mathbf{~} \text { ) }\end{array}$ \\
\hline 15 & 0.27614 & 0.01422 & 107.32 \\
20 & 0.25946 & 0.014167 & 88.89 \\
25 & 0.25887 & 0.014039 & 75.315 \\
30 & 0.28085 & 0.015005 & 61.273 \\
35 & 0.27125 & 0.01462 & 55.217 \\
\hline
\end{tabular}

\section{FUTURE SCOPE AND CONCLUSION}

- The ANSYS simulation results show the total deformation and normal stress in the composite materials. Steel has disadvantages of large deformation, higher weight and low corrosion resistance. These properties can be improved by reinforcing it with composites.

- A Reinforced concrete beam has been solved in the present problem.FEM software helps in solving the beam problem.

- In the above result, it is concluded that total deformation and directional deformation values(refer table 3) are low in $25 \mathrm{~mm}$ cover compared to other cases but the equivalent stress value $\left(55.217 \mathrm{~N} / \mathrm{mm}^{2}\right)$ is low in $35 \mathrm{~mm}$ cover size compared to $25 \mathrm{~mm}$ cover size $\left(75.315 \mathrm{~N} / \mathrm{mm}^{2}\right)$.

- Total deflection and directional deflection results have been analyzed. Equivalent elastic stress results have been referred to understand the behavior of $\mathrm{RC}$ beam with varying cover size under the application of two-point loading.

- By comparing the results, the effective value is obtained and the optimum cover size value is found to be $25 \mathrm{~mm}$. It also satisfies the IS800:2007 standards (table 6).

\section{REFERENCES}

[1] Shankar H. Sanni, Keshavraj. Girinivas," Analytical investigations on reinforced concrete beams",IRJET-Volume: 05 Issue: 12 | Dec 2018.

[2] Antonia F. Barbosa and Gabriel O. Ribeiro ," Analysis Of Reinforced Concrete Structures Using Ansys Nonlinear Concrete Model", Elsevier Science B.V.,2016.

[3] PeddiHema Arpitha Chowdary, Sreenu Bhuvanagiri, "Experimental Analytical and Investigation ofFlexural Behavior of Reinforced Concrete Beam",IJASTEMS-ISSN: 2454-volume.2, Issue.12,December.2016.

[4] T.S.Vishnu Kumar, N.Rushwanth Chowdary,"Finite Element Modeling Of RCC Beam By Using ABAQUS", ISSN: 2320-2882Volume 8, Issue 7 July 2020.
[5] User Manuel of ANSYS -12 from online (http://www.Ansys 12.co.in).

[6] Indian Standard Code of practice for plain and reinforced concrete IS: 456-2000, Bureau of Indian standards, New Delhi.

[7] Gopinath reddy and Muralidhara Rao,"Flexural behaviour of reinforced concrete beam Using ANSYS", CVIR Journal of science and technology, Volume 12, June 2017.

[8] AbdulsameeHalahla,"Study the Behavior of Reinforced Concrete Beam Using Finite Element Analysis",Budapest, Hungary - April 8-10, 2018 Paper No. ICSENM 103.

[9] V. S. Pawar, P. M. Pawar, "Modeling of Flexural Failure in Reinforced Concrete Beams as Under, Balanced and Over reinforced" International Journal of Engineering Trends and Technology, Volume 36, June 2016.

[10]Pradeepsingh, Abhishek Mishra, Arpit Kulshreshtha, "Finite element analysis of Reinforced Concrete Beam Using Ansys", International Journal of Current Engineering and Scientific Research, ISSN: 2394-0697, volume-3, issue-1, 2016.

[11] Kiran M. Malipatil, N.S. Badiger, "Parametric Study on Reinforced Concrete Beam using ANSYS", Civil and Environmental Research, ISSN: 2225-0514 (Online), Vol.6, No.8, 2014.

[12] Diyyala Naga Moulika, ReshmaVasireddy and P.PoluRaju, "Modelling And Analysis Of Reinforced. Concrete Beam under Flexure Using Ansys", International Journal of Civil Engineering and Technology (IJCIET), Volume 8, Issue 3, March 2017, pp. 1103-1111 Article ID: IJCIET_08_03_113.

[13] Vasudevan and Kothandaraman, G, "Parametric study on Nonlinear Finite Element Analysis on flexuralbehavior of RC beams using ANSYS", International Journal of Civil and Structural Engineering,2(1),pp-98-111. 